for many of the suggested studies being carried out without image intensification.

It would be impossible to list the subject material in detail, but the problems of tracheo-oesophageal fistula, hiatus hernia, reduplication of the gut, intestinal obstruction, Hirschprung's disease and imperforate anus are all dealt with in some detail and there is an entire chapter devoted to the difficult subject of the interpretation of plain films of the abdomen. Less common conditions such as mediastinal foregut duplication, necrotizing enterocolitis, meconium peritonitis are also included.

The book is well produced and illustrated. It is relatively expensive perhaps, reflecting the number of illustrations that it contains. It should be of great value for special care baby units and it is recommended to all doctors concerned with the care of the newborn.

\section{Management of Cardiac Arrest under hospital conditions by the resident home officer}

By John S. M. Zorab. Pp. 57, illustrated. Edinburgh and London: Churchill Livingstone, 1972. Book, £0.50; Cassette $£ 1.87$.

While on the face of it it would seem an admirable idea to have a booklet and cassette for the training of resident house officers in the management of cardiac emergencies, perusal of this publication together with the tape suggests that it is inadequate for this purpose. The amount of information is far too restricted, and indeed inferior in many respects to the printed cards that many hospitals utilize. Many will have different approaches to the management of cases, even if only in detail. An illustration of a monitor oscilloscope as an ECG machine, and the stressing of variations in the degree of ventricular fibrillation are unhelpful. Probably the strongest part of the book is the last section of text, but there is little here that does not already appear in print, such as in the instruction books provided by the manufacturers.

\section{Medicine for the Paramedical Professions}

Edited by Douglas W. PIPER. Pp. 339, illustrated. McGraw Hill Book Company Australia Pty. Ltd, 1970. Approx. $£ 4.00$. Treatment of the sick today involves a large number of individuals, viz. nurses, technicians, social workers, physiotherapists and dieticians. These workers belong to the socalled 'Paramedical Professions' and are supposed to have elementary knowledge of such subjects as anatomy, physiology, bacteriology and pathology. This book is primarily intended for these individuals and thirty-eight authors, each of whom is a specialist in his particular field, have contributed to this book.

There are 18 chapters. After an introductory chapter explaining common terms used in medicine, 8 chapters follow dealing with diseases affecting all the major systems. The next 7 chapters deal with a variety of subjects such as metabolic and deficiency diseases, due to physical and chemical agents, infectious diseases, diseases of the skin, illness and embolisms, common diseases of children and the use of radioactive isotopes in medicine. The last 2 chapters explain the common symptoms in medicine and discuss the managements of the unconscious and severely ill patient.

The book is well produced and should not only help members of the paramedical professions to deal efficiently with patients under their care, but communicate intelligently with the doctors. The book can be recommended to all those actively working for the welfare of the sick in various departments of a hospital.

\section{Workbook to accompany Medicine for the Paramedical} Professions

Edited by Douglas W. Piper. Pp. 136. McGraw Hill Book Company Australia Pty. Ltd, 1970. Approx. £1.50.
The preface states that this workbook is designed to be used specifically with Medicine for the Paramedical Professions. Questions are asked on the subjects discussed in each chapter and the right answer is found by reference to the pages given at the end of each question. The last chapter asks questions randomly on the subject-matter covered by the book and the editor states that the purpose of the workbook is for the reader to know for himself by answering the questions if he knows and understands his subject well, and this aim is fulfilled.

\section{Atlas of Hand Radiographs}

By PhiliP Jacobs, T.D., D.M.R.D., F.R.C.P., F.F.R Edited by P. JACOBS. Pp. 248, illustrated. London: Harvey, Miller and Metcalf, 1973. £7.00.

This beautifully produced atlas illustrates most conditions of the hand which the practising radiologist or clinician is likely to see in a radiograph. It will inevitably find a place in most medical libraries and X-ray departments and should become prescribed reading for radiologists in training and indeed for anyone in a speciality involving bone disease.

\section{Pharmacogenetics-Principles and Paediatric Aspects}

Edited by I. Szorady. Pp. 240, illustrated. Budapest: Akademial Kiado, 1973. $£ 5.50$.

Drug actions and interactions are now increasingly recognized to be a potent therapeutic hazard. In recent years, especially since the delineation of red-cell enzyme deficiencies, it has become appreciated that one of the reasons why individuals may vary in their tolerance of or reaction to drugs may lie in the field of inherited characteristics. The ethnif origin of patients becomes very important in deciding whicle drugs can be given and which should be withheld. This is noP just a subject for clinical pharmacologists who are evaluating new substances, but is of importance to every physician especially those who see patients of immigrant stock. It is therefore, extremely useful to have this comprehensiv analysis of this subject, with adequate detailed lists relating drugs to possible side-effects. The bibliography is compre hensive, and English-speaking as well as other sources ar quoted. It is well written and well translated, and deserve consideration for purchase as a reference book for all district general hospitals.

\section{Demonstrations of Physical Signs in Clinical Surgery (Hamilton Bailey)}

Edited by Allan Claim. Pp. 632, illustrated. Fifteenth edition. Bristol: John Wright, 1973. $£ 7.50$.

The fact that this is the fifteenth edition of the book and the previous editions have been translated in eight languages, provides unquestionable evidence that despite modern advances in laboratory and other auxiliary aids to diagnosis, doctors all over the world believe that a clinical diagnostician surgeon is still a master of his craft.

In this new edition Mr Claim has rearranged the order of chapters which should help a student in a systemic study of clinical surgery and alterations have been made to adopt the recommendations of the American Academy of Orthopaedic Surgeons on methods of measuring and recording joint movements. New material and illustrations demonstrating diagnostic signs in several common and rare diseases have been added.

This book has established its value over many years not only in the United Kingdom but all over the world and $\mathbf{M r}$ Claim deserves our thanks in employing Professor Ellis' words that there can be no substitute for detailed appraisal of the history and clinical signs. Every surgeon, however famous and great, should feel happy about this book and even the smallest medical library cannot be complete without it. It is handsomely produced and by today's standard the price is reasonable, but perhaps a bit stiff for a struggling grant-dependent medical student. 